\title{
Identification of Intracisternal A-Particle Like Element as an FSH Regulated Transcript in Immature Rat Sertoli Cells
}

\author{
Chitra Lekha Dahia and Addicam Jagannadha Rao*
}

Department of Biochemistry, Indian Institute of Science, Bangalore 560 012, India

\begin{abstract}
Sertoli cells under the influence of Follicle Stimulating Hormone are known to provide a microenvironment for the growth and differentiation of germ cells. Follicle Stimulating Hormone regulates proliferation of Sertoli cells only during the early neonatal period and during adult period it regulates functional parameters like Transferrin, Androgen binding protein and other factors needed for germ cell differentiation and how this is achieved is not known. In an attempt to understand the differential action of Follicle Stimulating Hormone on the Sertoli cells, we employed the approach of neutralization of endogenous Follicle Stimulating Hormone in neonatal rats for a very limited period and study the effect on the regulation of gene expression by Differential Display RT-PCR analysis. One of the transcripts was found to be down regulated following neutralization of endogenous Follicle Stimulating Hormone in the neonatal rats and it shared identity with Intracisternal A particle element, an endogenous retrovirus. Often integration of Intracisternal A particle into host genes and its regulation result in growth factor independence suggesting a role in proliferation. Interestingly, the expression of Intracisternal A particle transcript is not regulated by Follicle Stimulating Hormone in the adult rat Sertoli cells suggesting a possible reason for stimulation of proliferation of Sertoli cells by Follicle Stimulating Hormone only in the neonatal rats.
\end{abstract}

\section{INTRODUCTION}

Sertoli cells play a very crucial role in male reproduction by serving as nurse cells for the spermatogonial cells. The spermatogonial cells continue to divide, although the proliferation of Sertoli cells ceases shortly after birth in rodents. In rats, the Sertoli cell proliferation begins during the prenatal period and continues up to day 15-18 postnatal; beyond this period the Sertoli cells do not divide [1]. Follicle Stimulating Hormone (FSH) is the main mitogen for Sertoli cells [2-8]. The exit of Sertoli cells from the cell cycle does not appear to be due to decrease in FSH as its levels raises steadily during early postnatal development in rodents [9].

During our studies to understand the mechanism of differential response of Sertoli cells to FSH by way of proliferation only in the immature rat, we subjected the RNA isolated from purified Sertoli cells from normal monkey serum (NMS) and specific antiserum $(\mathrm{a} / \mathrm{s})$ to ovine $\mathrm{FSH}$ (FSH a/s) treated immature rat to differential display RTPCR (DD-RT-PCR) analysis. One of the differentially expressed transcripts was found to share the sequence with Intracisternal A Particle (IAP) like element and results of this study are presented in this paper. The objective of the present study is to investigate the possible significance of the decreased expression of IAP in Sertoli cells following neutralisation of endogenous FSH in immature male rats.

*Address correspondence to this author at the Department of Biochemistry, Indian Institute of Science, Bangalore 560 012, India; Tel: 918023608660 / 2293 2308; Fax: 918023600814 / 23600999 ;

E-mails: ajrao@biochem.iisc.ernet.in, ajrao_2000@yahoo.com

\section{MATERIALS AND METHODS}

\section{Animals and Treatment}

Seven-day old and 90-day old male Wistar rats were obtained from the Central Animal Facility, Indian Institute of Science, Bangalore, India and maintained under standard conditions (12 hrs of light and $12 \mathrm{hrs}$ of dark schedule, with water and pelleted food ad libitum). The animal procedures employed in the study have been approved by Institutional Ethical Committee.

Antiserum to highly purified OFSH was raised in adult male bonnet monkey (Macaca radiata). The absence of contaminating antibodies to Luteinizing Hormone (LH) was established by lack of binding to ${ }^{125} \mathrm{I}-\mathrm{hCG}$ (iodinated human chorionic gonadotropin). Also the antiserum when added to adult rat Leydig cells in vitro was unable to inhibit the stimulation of testosterone production by LH. The effect of antiserum to neutralize endogenous FSH was established in immature male rats $(\mathrm{N}=3)$. Normal monkey serum $(\mathrm{NMS})$ administered rats served as controls [10].

Seven-day old immature rats were administered $200 \mu \mathrm{L}$ of FSH a/s or NMS for five days by i.p. route. The effect of FSH deprival was monitored by analyzing the proliferation per se by determining the BrdU incorporation and analyzing the effect on the cell proliferation markers. As a source of Sertoli cells from adult animals, 90-day old adult rats were administered $300 \mu \mathrm{L}$ of FSH a/s or NMS by i.p. route twice a day for 5 days and on the sixth day Sertoli cells were isolated and processed as in the case of immature rats. 


\section{Isolation of Sertoli Cells and Culture}

Sertoli cells were isolated from immature rats by previously described protocol $[10,11]$. Sertoli cells were isolated from adult rats using a similar protocol employed for immature rats except with some modifications [11]. Briefly, seminiferous tubules were digested in $0.15 \%$ of Trypsin (Sigma Chemicals Co. St. Louis, MO) and $10 \mu \mathrm{g} / \mathrm{ml}$ of DNase (Worthington) in $1 \mathrm{X}$ HBSS for $20 \mathrm{~min}$. After three washes in $1 \mathrm{X}$ HBSS the tubules were subjected to two enzymatic digestions with $1 \mathrm{mg} / \mathrm{ml}$ collagenase (Worthington) and DNase followed by $1 \mathrm{mg} / \mathrm{ml}$ collagenase, $1 \mathrm{mg} / \mathrm{ml}$ hyaluronidase (Sigma Chemicals Co. St. Louis, MO) and DNase for $30 \mathrm{~min}$ each. The cells were washed thrice with $1 \mathrm{X}$ HBSS and pelleted down by centrifugation. The cells were resuspended in $1 \mathrm{ml}$ of Dulbeco's Minimum Essential Medium (DMEM) Ham's-F12 (Sigma Chemicals Co. St. Louis, MO) and counted on hematocytometer chamber. Immature Sertoli cells were maintained in DMEM Ham's-12 medium containing $10 \mu \mathrm{g} / \mathrm{ml}$ insulin (Sigma Chemicals Co. St. Louis, MO) and $5 \mu \mathrm{g} / \mathrm{ml}$ transferrin (Sigma Chemicals Co. St. Louis, $\mathrm{MO}$ ) at $32^{\circ} \mathrm{C}$ in $5 \% \mathrm{CO}_{2}$. After $24 \mathrm{hrs}$ of preculture Sertoli cells were subjected to hypotonic shock by replacing the medium with medium:water::1:10. The purified Sertoli cells were either used for isolation of RNA or protein or for in vitro incubation. Purified immature and adult rat Sertoli cells were incubated for $8 \mathrm{hrs}$ in medium containing $250 \mathrm{ng} / \mathrm{mL}$ OFSH for the in vitro studies (OFSH was a kind gift from Dr. M. R. Sairam, IRCM, Montreal) or vehicle (medium only). Viability of the immature and adult rat Sertoli cells at the end of experiments was assessed by MTT (3-4-,5 dimethylthizol-2yl2,5 ,diphenyl-tetrazolium) assay as described earlier [12]. The purity of the Sertoli cells was determined by assessing for the absence of germ cells as monitored under the phase contrast microscope. The purity of the Sertoli cells was more than $95 \%$. This was possible as on day 13 after birth the testis will mostly have Sertoli cells and germ cells and Sertoli cells are three times the size of germ cells and they can be easily distinguished under phase contrast microscope. The absence of Leydig cells and myoid cells in the Sertoli cell preparation was ascertained by checking for LH receptor by RT-PCR and staining for alkalinephosphatase respectively [10].

\section{BrdU Incorporation Assay}

Fifty thousand Sertoli cells from FSH a/s or NMS treated immature rats were cultured in two sets of triplicates in a serumfree (DMEM Ham's-F12) medium supplemented with insulin $(10 \mu \mathrm{g} / \mathrm{mL})$ (Sigma Chemical Co., St. Louis, MO, USA), and transferrin $(5 \mu \mathrm{g} / \mathrm{mL})$ (Sigma Chemical Co., St. Louis, MO, USA) along with or without $250 \mathrm{ng} / \mathrm{mL}$ of OFSH. Cells were cultured at $32^{\circ} \mathrm{C}$ in $5 \% \mathrm{CO}_{2}$. After $16 \mathrm{hrs}$, the cells were pulsed with $10 \mu \mathrm{M}$ BrdU and incubated for $4 \mathrm{hrs}$. The BrdU incorporation was assessed using Cell Proliferation ELISA Biotrak $^{\mathrm{TM}}$ System as per the manufacturer's protocol (Amersham-Pharmacia Biotech., UK). Briefly, the medium was removed and the cells were fixed in $100 \mu \mathrm{L}$ of fixative for half an hour. The fixative was removed and the wells were blocked by adding $200 \mu \mathrm{L}$ of 1:10 diluted blocking buffer for another half an hour. The wells were then incubated with $\alpha$-BrdUhorseradish-peroxidase (HRP) conjugated monoclonal antibody, diluted (1:100 in antibody dilution solution), for $90 \mathrm{~min}$. The wells were washed three times in 1:10 diluted wash buffer. Color was developed by incubating the wells with the HRP substrate 3,3',5,5'-tetramethylbenzidine (TMB). The reaction was stopped using $1 \mathrm{M} \mathrm{H}_{2} \mathrm{SO}_{4}$ and the optical density was determined in the ELISA reader (Molecular Devices) at 450 $\mathrm{nm}$. Viability of the Sertoli cells at the end of experiments was analyzed by MTT assay.

\section{Semi-Quantitative RT-PCR}

Total RNA was extracted from cells or tissues using TRI $^{\circledR}$ reagent (Sigma Chemical Co., St. Louis, MO, USA). RT-PCR was carried out as previously described (10). PCR amplification was carried out using specific primers [Cyclin A2 FP 5'CGTGGACTGGTTAGTTGA3'; Cyclin A2 RP 5'A TGGCAAATACTTGAGGT3'; Cyclin E FP 5'CATGGAAC TGATGATGATGAA3'; Cyclin E RP 5'CTCCAACGAGG AAAAATGATA3'; Cyclophilin FP 5'GTGGCAAGTCCAT CTACG3'; Cyclophilin RP 5'CAGTGAGAGCAGAGATT ACA3'; IAP FP 5'CGATGGAAGCCTTGGTTT3'; IAP RP 5'GCTTCCTCACATCGTTTATCC3'; $p 27^{\text {kipl }}$ FP 5'CAGC TTGCCCGAGTTCTA3'; $p 27^{k i p l}$ RP 5'TCGGGGAACCGT CTGAAAC3']. Cyclophilin was used as an internal control.

\section{Differential Display RT-PCR Analysis}

Total RNA, free of genomic DNA with an A260/280 ratio of 1.8 and above was used for the DD-RT-PCR analysis as described by Linskens [13], which is a modified protocol of Liang and Pardee [14]. In brief, $1 \mu \mathrm{g}$ of RNA was reverse transcribed with anchored primer of sequence 5, GCGCAAGCTTTTTTTTTTTTNN 3' (N=A, G, C or T). A control reaction without adding reverse transcriptase was included to confirm the absence of non-specific amplification from genomic DNA. The cDNA corresponding to $40 \mathrm{ng}$ of RNA was PCR amplified using arbitrary primer of sequence 5' CGGGAAGCTTGCTAAGACTAGC 3' in the presence of $\alpha^{32} \mathrm{P}-\mathrm{dCTP}$. The PCR conditions involved four cycles of low stringency $\left(94^{\circ} \mathrm{C}-45 \mathrm{~s}, 41^{\circ} \mathrm{C}-60 \mathrm{~s}, 72^{\circ} \mathrm{C}\right.$ $60 \mathrm{~s})$ and 18 cycles with high stringency $\left(94^{\circ} \mathrm{C}-45 \mathrm{~s}, 60^{\circ} \mathrm{C}-45\right.$ $\mathrm{s}, 72^{\circ} \mathrm{C}-120 \mathrm{~s}$ ) followed by primer extension at $72^{\circ} \mathrm{C}$ for 10 min. The electrophoresis of heat denatured PCR products was carried out on urea-PAGE gel ( $6 \%$ polyacrylamide and $48 \%$ urea). The gels were dried and exposed to X-ray film for 10-12 hrs. The cDNA bands which were differentially displayed on the radiograph were excised with a sterile razor and soaked in TE to release cDNA The solution containing cDNA was PCR amplified using the same set of anchored and arbitrary primers which were used in the DD-RT-PCR. The PCR-amplified cDNA was sequenced and the sequence identity was established by carrying out BLAST analysis in the NCBI nucleotide database.

\section{Multiple Sequence Alignment}

Multiple alignments of two or more DNA sequences were carried out using the multiple sequence alignment program ClustalW 1.8 at the BCM search launcher [15] (http://searchlauncher.bcm.tmc.edu). The program aligns the first entered sequence to all other sequences entered. Shading of the multiple alignments was carried out using the program BOXSHADE 3.21 (EMBnet server;http://www.ch.embnet. org/software/BOX_form.html).

\section{Northern Blot Analysis}

Poly A + RNA was isolated from highly purified Sertoli cells from immature male rats and subjected to Northern blot analysis as described earlier [16]. The gag region of IAP 
(with the sequence of the transcript identified during DD RT-PCR analysis) was used as a probe. The blot was washed at $65^{\circ} \mathrm{C}$ twice in $2 \mathrm{x}$ SCC for 10 min followed by two washes in $0.2 \mathrm{x}$ SCC and $0.2 \% \mathrm{SDS}$ for $15 \mathrm{~min}$ each. The blot was exposed to phosphor-imager screen for detection of the signal. 18S rRNA was used as an internal control.

\section{Western-Blot Analysis}

For Western blot, cells were homogenized in ice-cold phosphate buffered saline (PBS) ( $\mathrm{pH}$ 7.4) containing complete Protease Inhibitors (Roche Molecular Biochemicals, Germany, diluted according to manufacture's instructions) according to previously described procedures [17]. Western-blot analysis was carried out using standard protocol with mouse monoclonal antibodies for PCNA, CYCLIN D1 (Santa Cruz, CA, USA) and $\alpha$-Tubulin (Calbiochem, Germany), and rabbit polyclonal antibody for $\mathrm{p} 27^{\mathrm{kip} 1}$ (Santa Cruz) at a dilution of 1:400. Bound antibody was visualized using Enhanced Chemi Luminescence (ECL) kit and ECL films (Amersham Pharmacia Biotech., UK) according to manufacture's instructions. Analysis of images was carried out using Kodak Electrophoresis and Gel Documentation Analysis System (EDAS-120).

\section{Statistical Analysis}

Data are represented as Mean \pm SEM of at least three separate experiments performed using the same treatment protocol. For statistical comparison among groups involving only two columns (RT-PCRs, Northern blot and Western blot analysis of Sertoli cells), significance was evaluated using the unpaired two-tailed t-test. For comparison of data comprising three or more columns statistical significance was evaluated using the two-way ANOVA test. In both instances, a 'P' value less than or equal to 0.05 was considered to be statistically significant.

\section{RESULTS}

\section{Effect of FSH Deprival on Sertoli Cell Proliferation}

The importance of FSH in the proliferation of Sertoli cells during the early neonatal period was assessed using the in vivo model system. The deprival of endogenous FSH for five days (from day seven to day eleven) using a specific antiserum to $\mathrm{FSH}$ resulted in $90 \%$ decrease in BrdU incorporation in Sertoli cells compared to NMS treated control rat Sertoli cells (Fig. 1A). The stimulation in proliferation of Sertoli cells isolated from FSH deprived group following addition of OFSH $(250 \mathrm{ng} / \mathrm{mL})$ was much less than that observed in the NMS treated group in which nearly two-fold increase in the proliferation was observed (Fig 1A).

RT-PCR analysis was carried out for the cell cycle markers which are involved in the G1-S phase transition. It was observed that following neutralization of endogenous FSH in immature rats there was a significant $(\mathrm{P}<0.05)$ decrease in the level of mRNA expression of Cyclin A2 and Cyclin $E$ in Sertoli cells from FSH a/s treated rats compared to the Sertoli cells isolated from NMS treated control rats (Fig. 1B). It was also observed that the expression of mRNA for $p 27^{k i p l}$ (which is a cell cycle inhibitor protein) significantly $(\mathrm{P}<0.05)$ increased in Sertoli cells following deprival of endogenous FSH in the immature rats compared to the NMS treated control (Fig. 1B). Cyclophilin was used as an internal control.

Western blot analysis was carried out for CYCLIN D1, which is an important molecule involved in the progression of cell cycle from the G1 phase beyond the restriction point. Western blot analysis results revealed that the level of CYCLIN D1 was significantly $(\mathrm{P}<0.01)$ reduced following neutralization of endogenous FSH. Proliferating cell nuclear antigen (PCNA) is a cell cycle marker. PCNA is a subunit of DNA $\delta$-polymerase which is associated with DNA replication, and hence cell division. The level of PCNA was significantly reduced $(\mathrm{P}<0.05)$ following neutralization of endogenous FSH as assessed by Western blot.

In addition, Western blot analysis, confirmed that even the protein level of $\mathrm{p} 27^{\mathrm{kip} 1}$ was significantly increased $(\mathrm{P}<$ 0.01 ) in the Sertoli cells following deprival of endogenous FSH in immature rats (Fig. 1C). Western blot for $\alpha$-Tubulin was used as an internal control.

\section{DD-RT-PCR Analysis}

In an attempt to assess the involvement of FSH regulated genes in mediating the differential action of FSH on Sertoli cells from immature and adult rats, the effect of neutralization of endogenous FSH in immature rats was assessed. DD-RT-PCR analysis was carried out using RNA isolated from Sertoli cell of NMS and FSH antiserum treated immature rats. Although efforts were made to establish the identity of several transcripts which were differentially regulated between the NMS and FSH antiserum treated groups, the identity of only one transcript could be established with certainty. This transcript was found to be down regulated in the $\mathrm{FSH}$ antiserum treated group of immature rat Sertoli cells (Fig. 2A).

The transcript was purified and sequence analysis revealed that this transcript corresponding to $194 \mathrm{bp}$ shared $90 \%$ identity with IAP (Fig. 2B) and the sequence accession number for IAP used in the sequence alignment is U23776.1. IAPs are endogenous retrotransposon, which are found in more than 1000 copy number in the rat genome [18-21]. They consist of three genes gag, pol and env. The env gene is defective due to multiple stop codons and mutations and thus these retroviruses lack an extra cellular phase and are not infectious [21].

\section{Validation of the DD-RT-PCR Analysis Results}

The differential expression of IAP was confirmed by RTPCR and Northern blot analysis (Fig. 3A, B). The results of RT-PCR analysis confirmed that following deprival of endogenous $\mathrm{FSH}$ in immature rats there was a significant $(\mathrm{P}<0.01)$ decrease in the level of expression of mRNA for IAP in immature rat Sertoli cells. Northern blot analysis revealed that the transcript of size $1.9 \mathrm{~kb}$ was down regulated following neutralization of endogenous FSH in immature rats (Fig. 3B). The regulation of expression for IAP by FSH in the immature rat Sertoli cells was also confirmed under in vitro conditions. When the Sertoli cells isolated from immature rats were cultured in the presence of FSH, a significant $(\mathrm{P}<0.01)$ increase in the expression of IAP was observed (Fig. 3C). 
(A)

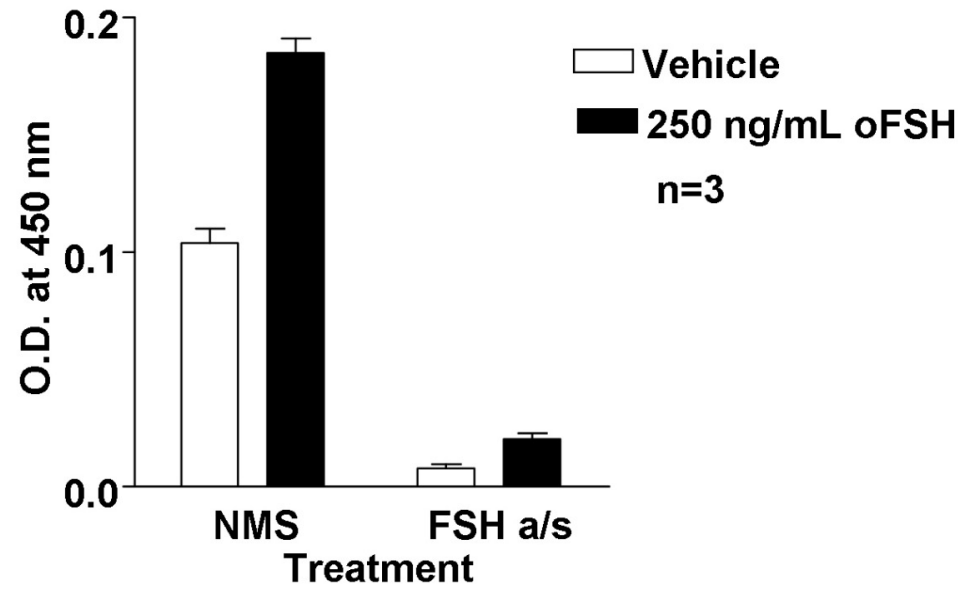

(B)

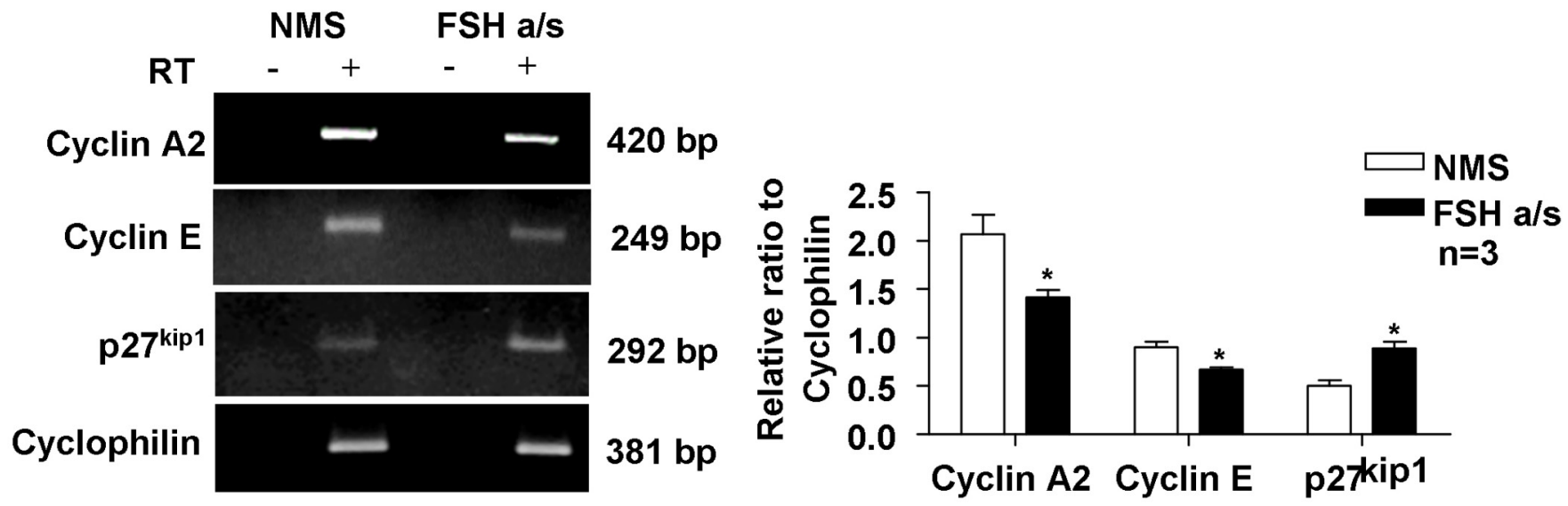

(C)

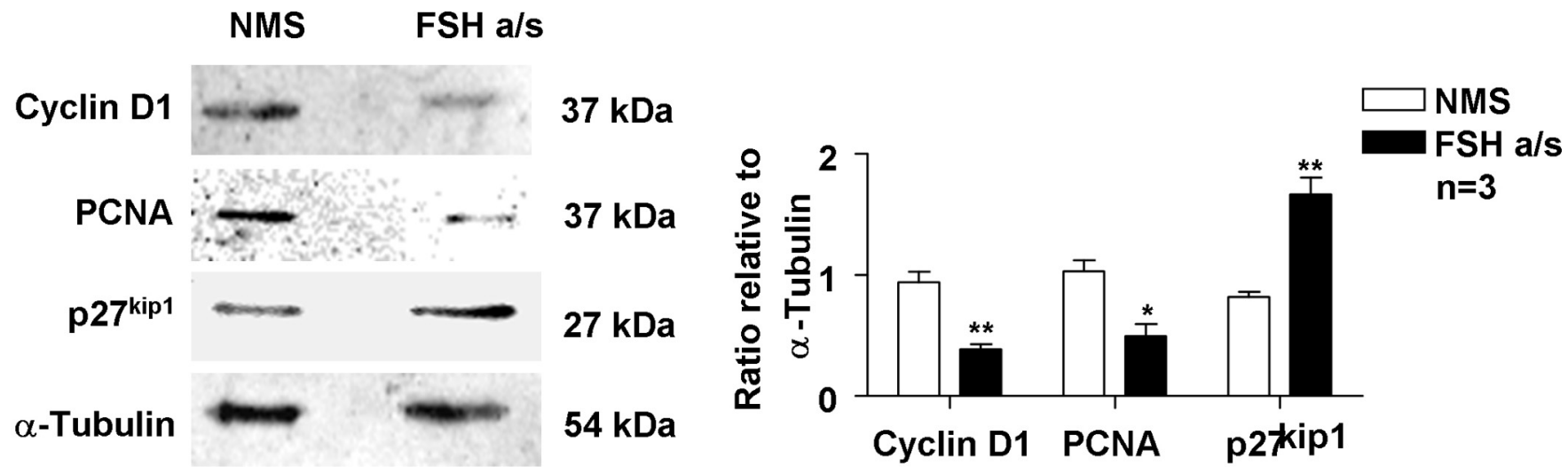

Fig. (1). Effect of neutralization of endogenous FSH on proliferation. (A) Neutralization of endogenous FSH in immature rats resulted in the decrease in the proliferation of Sertoli cells as analyzed by BrdU incorporation assay. Addition of FSH to the Sertoli cells isolated from FSH a/s treated immature rats did not increase the incorporation of BrdU and hence the proliferation of Sertoli cells. (B) RT-PCR analysis for cell proliferation markers revealed that the mRNA expression of cyclin A2, cyclin E was significantly decreased (P<0.05) whereas the mRNA expression of cell cycle inhibitor p27kip1 was significantly increased $(\mathrm{P}<0.05)$ in Sertoli cells following neutralization of endogenous FSH in immature rats. (C) Western blot analysis of NMS and FSH a/s treated immature rat Sertoli cells for cell proliferation markers revealed that the level of cyclin D1 $(\mathrm{P}<0.01)$ and PCNA $(\mathrm{P}<0.05)$ was significantly reduced following FSH deprival. Western blot analysis result also confirmed the RT-PCR results that the expression of cell cycle inhibitor $\mathrm{p} 27 \mathrm{kip} 1$ was significantly up-regulated (P< 0.01$)$ following deprival of endogenous FSH in immature rats. The figures are representative of three independent experiments. The values represent Mean \pm SEM. 
(A)

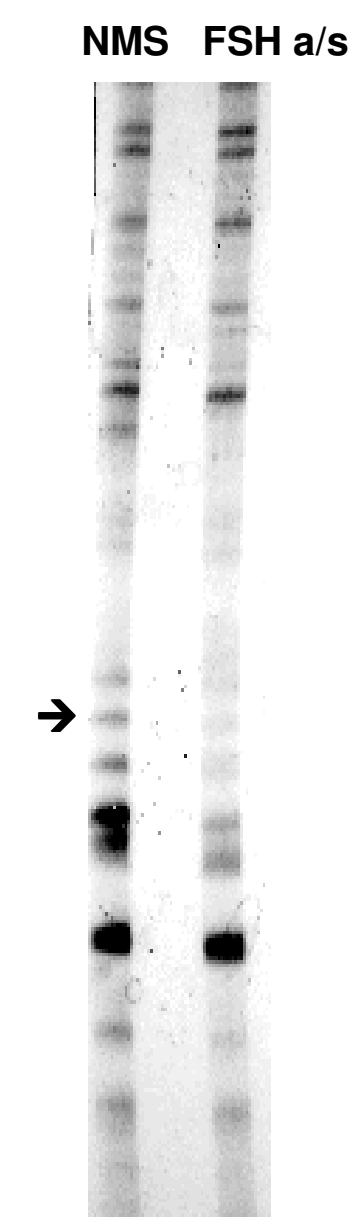

(B)
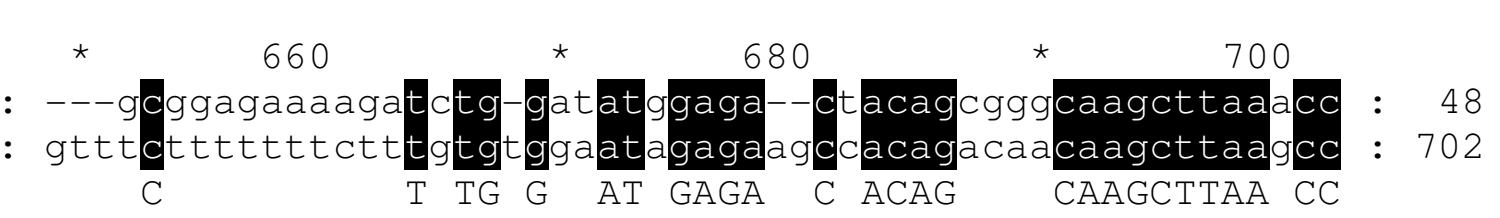

Transcript : : $---g$ cgga
: gtttctt

gaaaag C ttttct

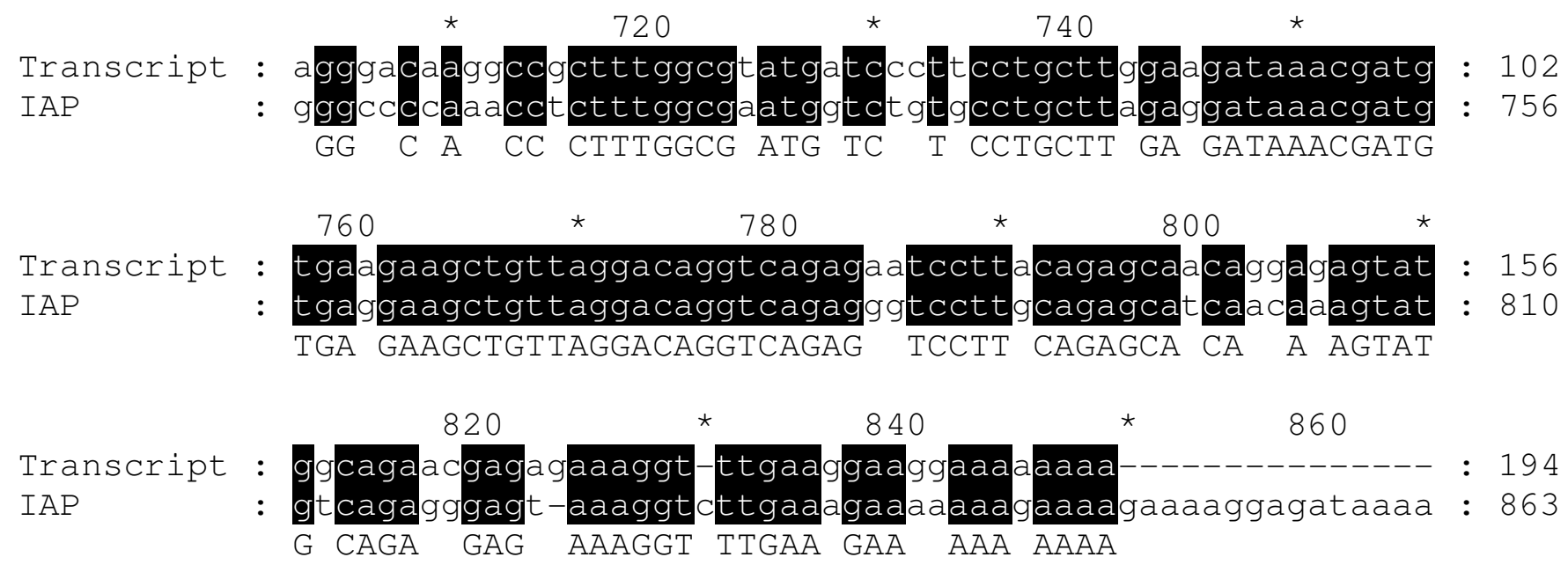

Fig. (2). DD-RT-PCR analysis: (A) Autoradiograph of the DD-RT-PCR carried out on the RNA isolated from NMS and FSH a/s treated immature rat Sertoli cells. One of the transcripts was found to be down-regulated in Sertoli cell following neutralization of endogenous FSH in immature rat (marked with the arrow). (B) Box-shade analysis of the sequence of the differential expressed transcript with an endogenous retrotransposon namely Intracisternal A particle element (IAP) with which it shared $90 \%$ identity. 
(A)

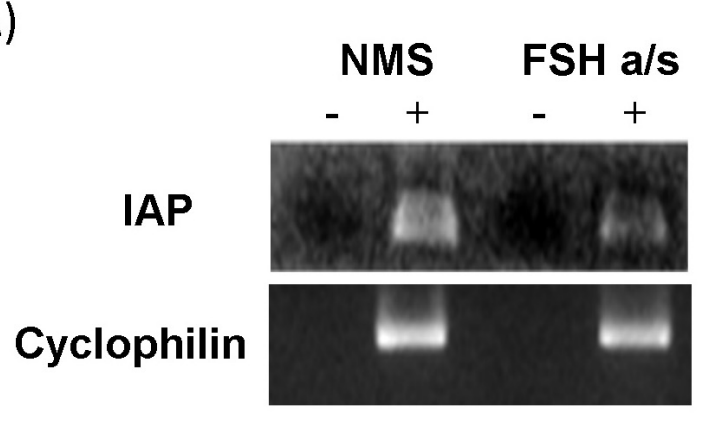

(B)

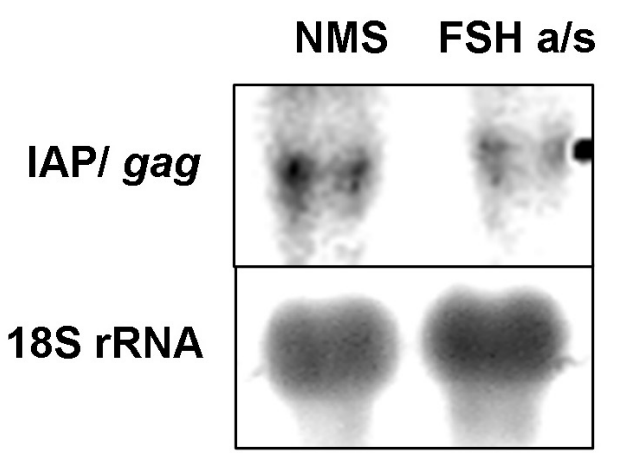

$1.9 \mathrm{~kb}$

$1.8 \mathrm{~kb}$
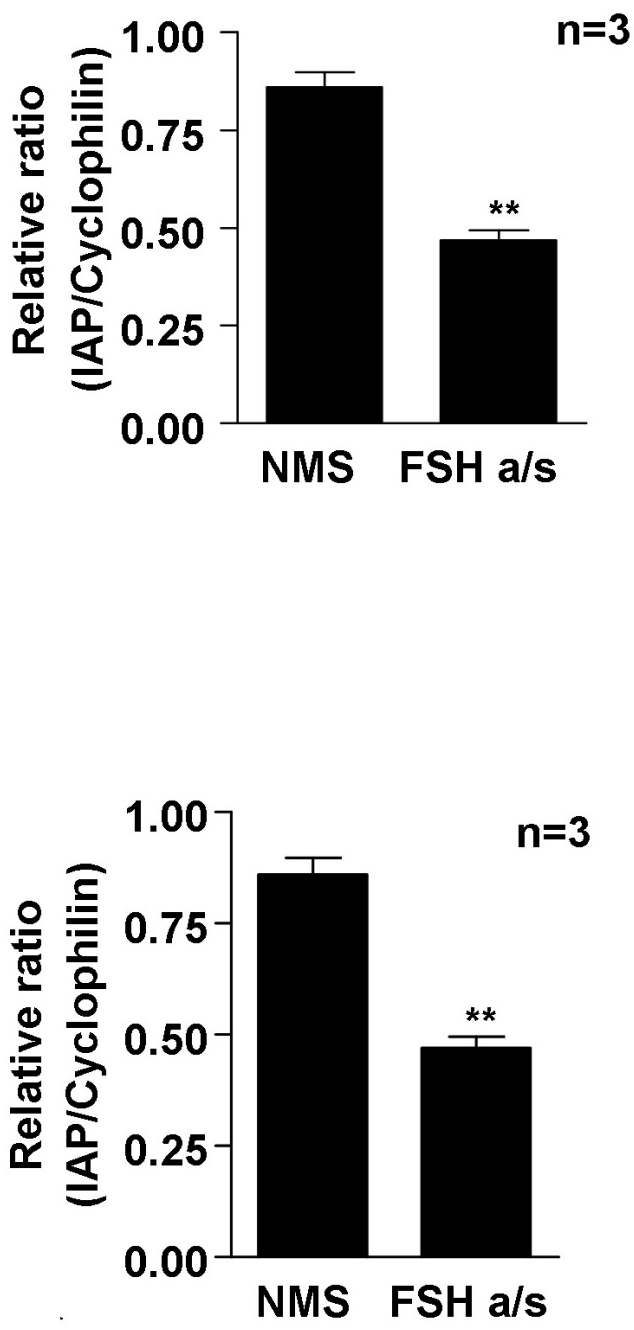

(C)

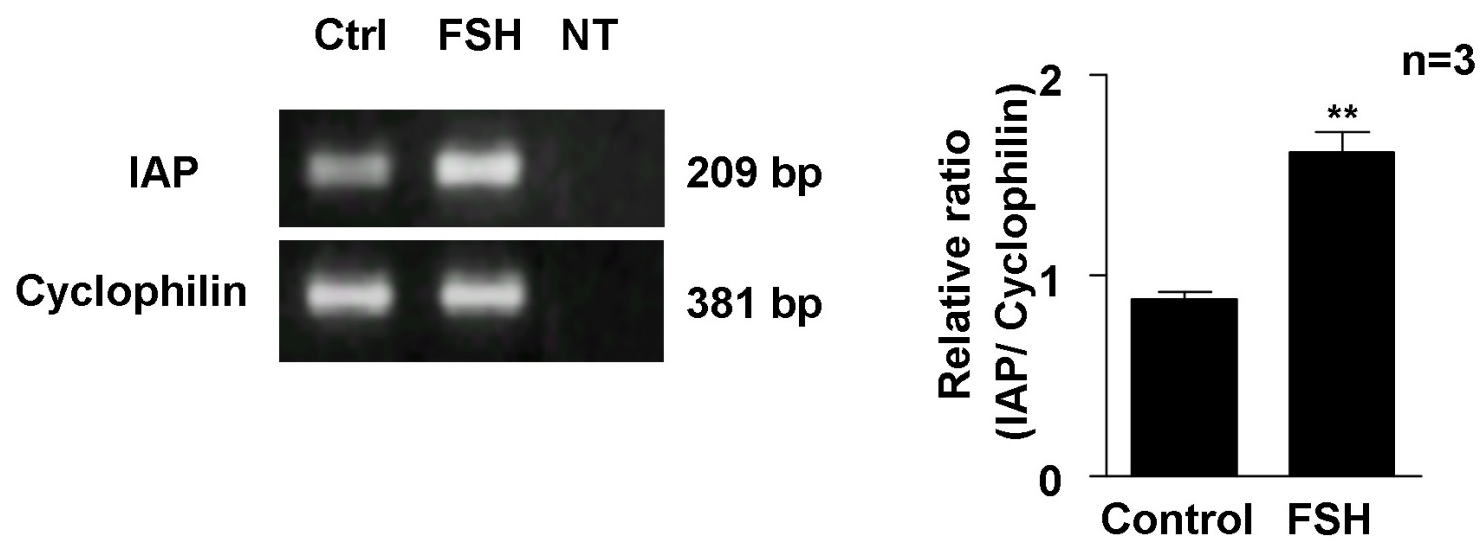

Fig. (3). Validation of the Differential expression of IAP. (A) RT-PCR analysis revealed a significant $(\mathrm{P}<0.01)$ decrease in the expression of IAP in Sertoli cells following neutralization of endogenous FSH in immature rat. (B) Northern blot analysis also confirmed that the expression of IAP was significantly decreased $(\mathrm{P}<0.01)$ following neutralization of endogenous FSH in immature rats. (C) Regulation of IAP in immature Sertoli cells in vitro. RT-PCR analysis of RNA isolated from immature rat Sertoli cells cultured in the presence of 250 $\mathrm{ng} / \mathrm{mL}$ of OFSH revealed significant $(\mathrm{P}<0.01)$ increase in the expression of IAP. The figures are representative of three independent experiments. The values represent Mean $\pm \mathrm{SEM}$. 


\section{Comparison of Expression of IAP in Immature and Adult Rat Sertoli Cells}

As the objective of the present investigation was to compare the immature and adult rat Sertoli cells for differential response to FSH, RT-PCR analysis was carried out to monitor the level of expression of IAP using RNA isolated from the immature and adult rat Sertoli cells. Results revealed that the level of expression of IAP was same in Sertoli cells isolated from both groups of animals (Fig. 4A).

\section{Regulation of IAP Expression by FSH in Adult Rat Sertoli Cells}

RT-PCR analysis carried out to monitor the regulation of IAP by FSH in adult rat Sertoli cells revealed that following deprivation of endogenous $\mathrm{FSH}$ using $\mathrm{FSH}$ a/s, there was no effect on the level of expression for IAP (Fig. 4B). Thus, the expression of IAP was regulated by FSH only in the immature rat Sertoli cells and not in the adult rat Sertoli cells. In this connection, it should be noted, the fact that there was a significant decrease in the level of transferrin mRNA as assessed by RT-PCR following administration of antiserum to FSH to adult rat establishes its efficacy of neutralizing endogenous FSH in adult rats [10].

\section{DISCUSSION}

Actions of FSH on Sertoli cells include rapid cellular proliferation, inhibition of apoptosis, steroidogenesis and differentiation [22]. The importance of these events is to sustain optimal production of viable sperms. In an earlier study [10], molecular analysis for the cell cycle markers Cyclin A2 and PCNA in the 10-day and 90-day old rat Sertoli cells revealed that the Sertoli cells are nonproliferative during the adult stages, although it is established that FSH is not a limiting factor in the adult [2325]. In earlier studies [10] we have shown that the differential action of FSH on Sertoli cells is mediated at the level of regulation of $\mathrm{FSH}$ receptor, $\mathrm{Ca}^{2+}$ signaling, PKI $\beta$ and IL-6.

The inhibition of the Sertoli cell proliferation by neutralization of endogenous FSH was validated by analyzing the proliferative status of the cells by BrdU incorporation assay as well as by checking for the level of cell proliferation markers like Cyclin A2, Cyclin E, CYCLIN D1 and p2 $7^{\text {kip1 }}$ (Fig. 1).

In an attempt to identify the possible basis of the differential action of FSH with respect to the proliferation of the Sertoli cells, DD-RT-PCR analysis was carried. One of the transcripts which was found to be down regulated following deprival of endogenous FSH showed similarity to retrotransposon known as IAP (Fig. 2). The regulation of IAP by FSH in the immature rat Sertoli cells was validated by RT-PCR as well as Northern blot analysis, confirming the authenticity of the DD-RT-PCR results. The results obtained from the in vivo studies were confirmed using the in vitro system, wherein Sertoli cells isolated from the adult rats were cultured in the presence of OFSH. Analysis of RNA by RT-PCR for the level of expression of IAP, revealed that addition of FSH did not have any effect on the level of IAP in the adult rat Sertoli cells (Fig. 4). However, it should be noted that the level of expression of IAP as assessed by semi-quantitative RT-PCR did not differ between the immature and adult rat Sertoli cells (Fig. 4). It is possible that the regulation of IAP is only in the immature rat Sertoli cells and not the absolute level of expression determines the proliferation of Sertoli cells by FSH.

In their more complete form, IAPs have a genome analogous to that of retroviruses except that they have env gene defect(s). The env region contains multiple stop codon in all reading frames and thus the retrotransposons are unable to exit from the cells [21]. IAPs are found in more than 1000 copy number in the rat genome [18-21, 26, 27]. IAP like other endogenous retroviruses can integrate into genes of their host and hence can be regulated along with those genes. It is possible that activation or inactivation of genes by novel integration of IAP elements contributes to tumorigenicity of the cells [21], suggesting a role in proliferation. Based on the results obtained in the present study one can argue that the suggested link between IAP and cell proliferation is based on circumstantial evidence. However, it is known that retroviral genes that have been integrated into the genome are bordered by short direct repeats of host DNA and LTR sequences of about 500-600 nucleotides. These LTR can influence neighbouring genes because they may contain transcriptional regulatory elements such as enhancers, promoters, hormone responsive elements and polyadenylation sites [28]. Recently the presence of retrovirus SC1 in prepubertal Sertoli cells and granulosa cells has been reported by other groups also [29]. In this connection it is pertinent to note that Type $\mathrm{C}$ retroviruses have been found in the reproductive tissues of human and sub-human primates. One important feature is their apparent hormonal responsiveness. It is known that hormone responsive elements of MMTV are responsive to glucocorticoids [30], progestins, androgens and mineralocorticoids [31-33]. It has been shown that T47D human mammary carcinoma cell lines produces retroviral particles [34] with reverse transcriptase activity [35]. Both HERV-K-10 related sequences of T47D cells and the reverse transcriptase activity are increased by steroid hormone treatment. Interestingly, Sertoli cells are the site of estrogen production during the neonatal period as the enzyme responsible for the conversion of testosterone to estradiol, namely aromatase, is expressed in Sertoli cells of immature rats [36-38]. FSH action is important for the regulation of aromatase and the synthesis of estrogen in the Sertoli cell. Studies from our laboratory have demonstrated that the levels of estradiol, and aromatase decrease following neutralization of endogenous FSH [39]. It is also known that estrogen synthesis by Sertoli cells ceases by day 18 postnatally at which time proliferative response of the Sertoli cells to FSH also ceases. It is known that subsequently the synthesis of estrogen is taken over by the Leydig cells. Thus considering all the above facts it is possible that IAP could have integrated in to gene(s) which are regulated by estrogen. Because estrogen synthesis in response to FSH ceases by day 18 postnatally, it is possible that proliferative response to FSH in immature rat Sertoli cells also ceases. In the present study, although we have not been able to establish the gene in to which IAP could have integrated, we believe that we have been able to provide sufficient evidence based on which, we can possibly conclude that it is regulated by FSH and suggest its possible 
(A)

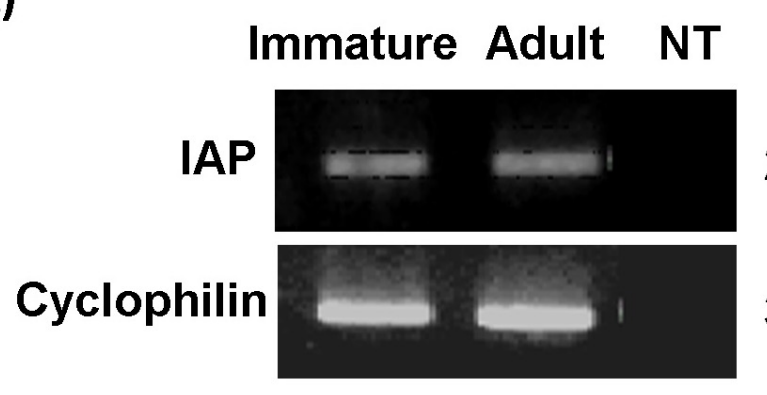

$381 \mathrm{bp}$

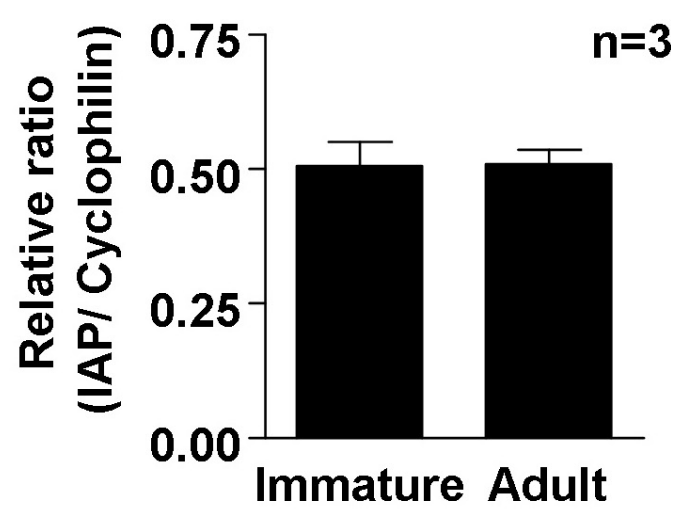

(B)

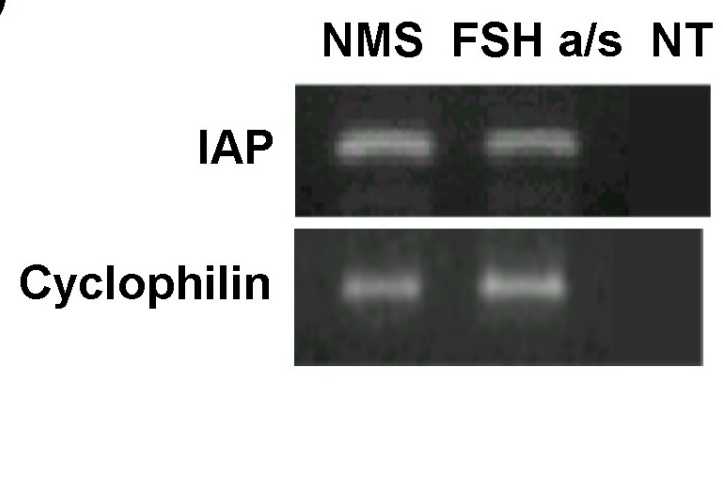

209 bp

$381 \mathrm{bp}$

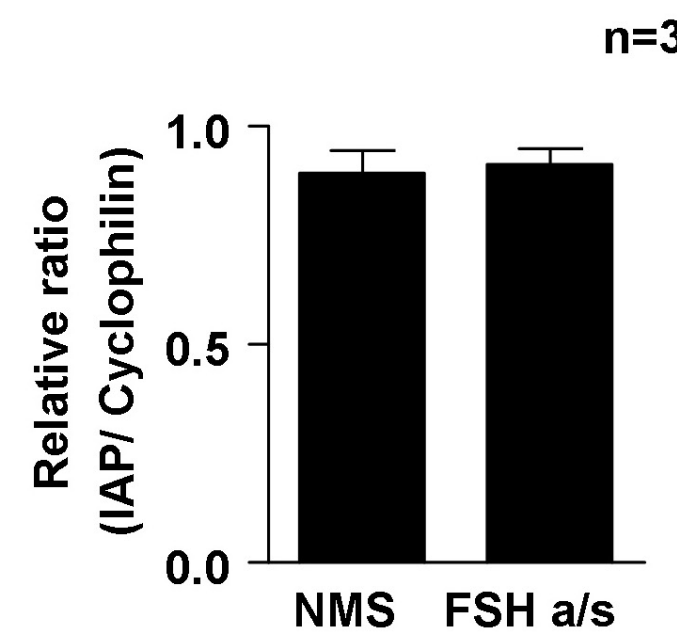

(C)

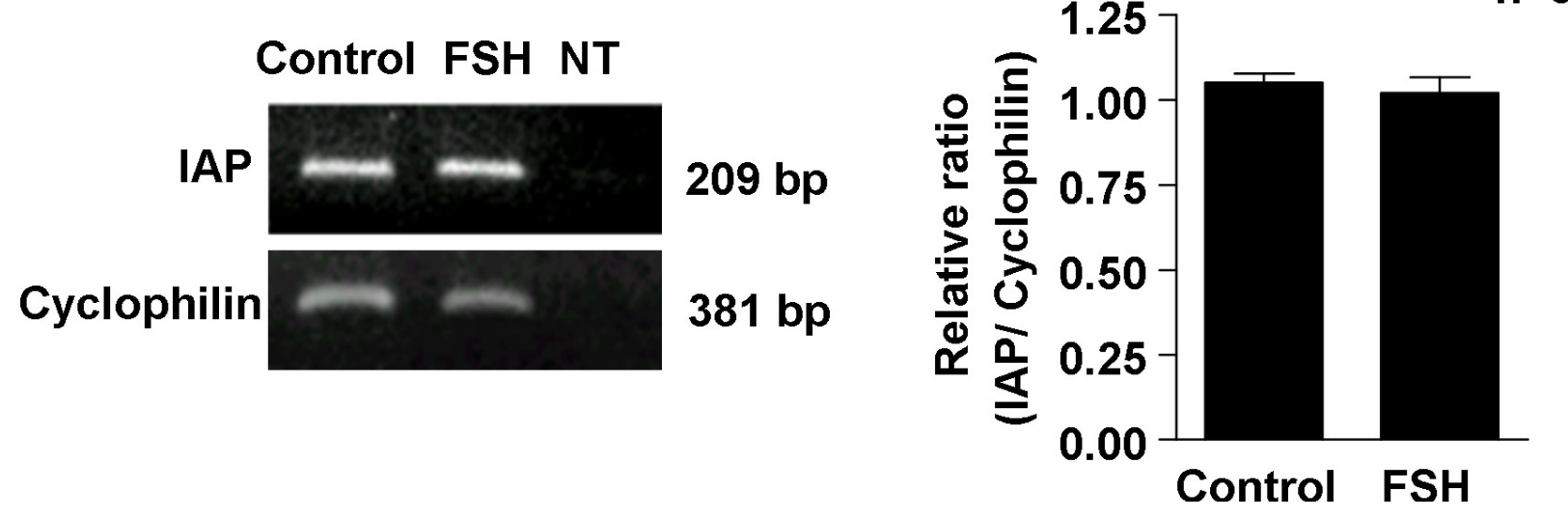

Fig. (4). Comparison of IAP expression in immature and adult rat Sertoli cells. (A) RT-PCR analysis for comparison of expression of IAP in the Sertoli cell isolated from the immature and adult rat showed that level of expression is same in both the stages. (B) Regulation of expression of IAP by FSH in adult rat Sertoli cells. The expression of IAP in the NMS and FSH a/s treated adult rat Sertoli cells was same as revealed by RT-PCR analysis. (C) Addition of $250 \mathrm{ng} / \mathrm{mL}$ of OFSH to the adult rat Sertoli cells in culture also did not increase the expression of IAP as observed by RT-PCR analysis. The figures are representative of three independent experiments. The values represent Mean \pm SEM. 
involvement in regulation of proliferation directly or indirectly by FSH. Thus, the regulation of IAP by FSH observed only in the immature Sertoli cells could be of significance in mediating the differential action of FSH. However, it should be noted that several other factors may be involved in regulation of the proliferation of Sertoli cells, and the integration of IAP could be one of them.

In summary, The results of our study based on DDRTPCR analysis of RNA from Sertoli cells isolated from NMS and the FSH antiserum treated immature rats suggests that one of the possible reasons for the proliferative response of Sertoli cells to FSH only in immature rat, could be due to insertion of IAP into a gene which could possibly be directly regulated by $\mathrm{FSH}$ or indirectly through estrogen only in the immature rat Sertoli cell.

\section{ACKNOWLEDGEMENTS}

AJR is thankful to Department of Science and Technology for the award of Rajarammanna Fellowship. The authors wish to thank the Indian Institute of Science, Bangalore, Department of Science and Technology, Government of India, Mellon Foundation USA, CONRAD, USA, for the financial assistance provided during the course of the work.

\section{REFERENCES}

[1] Orth JM. Proliferation of Sertoli cells in fetal and postnatal rats: a quantitative autoradiographic study. Anat Rec 1982; 203: 485-92.

[2] Orth JM. The role of follicle-stimulating hormone in controlling Sertoli cell proliferation in testes of fetal rats. Endocrinology 1984; 115: 1248-55.

[3] Means AR, Huckins C. Coupled events in the early biochemical actions of FSH on the Sertoli cells of the testis. Curr Top Mol Endocrinol 1974; 1: 145-65.

[4] Russell LD, Steinberge RA. Sertoli cells in culture: views from the perspectives of an in vivoist and an in vitroist. Biol Reprod 1989; 41: 571-7.

[5] Dorrington JH, Roller NF, Fritz IB. The effects of FSH on cell preparations from the rat testis. Curr Top Mol Endocrinol 1974; 1: 237-41.

[6] Kumar TR, Wang Y, Lu N, Matzuk MM. Follicle stimulating hormone is required for ovarian follicle maturation but not male fertility. Nat Genet 1997; 15: 201-4.

[7] Dierich A, Sairam MR, Monaco L, et al. Impairing folliclestimulating hormone (FSH) signaling in vivo: targeted disruption of the FSH receptor leads to aberrant gametogenesis and hormonal imbalance. Proc Natl Acad Sci USA 1998; 95: 13612-7.

[8] Griswold MD, Mably ER, Fritz IB. FSH stimulation of DNA synthesis in Sertoli cells in culture. Mol Cell Endocrinol 1976; 4: 139-49.

[9] Dohler KD, Wuttke W. Changes with age in levels of serum gonadotropins, prolactin and gonadal steroids in prepubertal male and female rats. Endocrinology 1975; 97: 898-907.

[10] Dahia CL, Rao AJ. Regulation of FSH receptor, PKIbeta, IL-6 and calcium mobilization: possible mediators of differential action of FSH. Mol Cell Endocrinol 2006; 247: 73-81.

[11] Tung PS, Fritz BI. Isolation of Sertoli cells and Their Properties in Culture. In: Celis JE, Ed. Cell Biology A Laboratory Handbook, $2^{\text {nd }}$ ed. San Diego: Academic Press 1998.

[12] Rama S, Petrusz P, Rao AJ. Hormonal regulation of human trophoblast differentiation: a possible role for $17-\beta$-estradiol and GnRH. Mol Cell Endocrinol 2004; 218: 79-94.

[13] Linskens MH, Feng J, Andrews WH, et al. Cataloging altered gene expression in young and senescent cells using enhanced differential display. Nucleic Acids Res 1995; 23: 3244-51.
[14] Liang P, Pardee AB. Differential display of eukaryotic messenger RNA by means of the polymerase chain reaction. Science 1992; 257: $967-71$.

[15] Jeanmougin F, Thompson JD, Gouy M, Higgins DG, Gibson TJ Multiple sequence alignment with Clustal X. Trends Biochem Sci 1998; 23: 403-5.

[16] Dahia CL, Rao AJ. Demonstration of follicle-stimulating hormone receptor in cauda epididymis of rat. Biol Reprod 2006; 75: 98-106.

[17] Sairam MR, Jiang LG, Yarney TA, Khan H. Alternative splicing converts the G-protein coupled follitropin receptor gene into a growth factor type I receptor: implications for pleiotropic actions of the hormone. Mol Reprod Dev 1997; 48: 471-9.

[18] Lueders KK, Kuff EL. Sequences associated with intracisternal A particles are reiterated in the mouse genome. Cell 1977; 12: 96372.

[19] Ono M, Cole MD, White AT, Huang RC. Sequence organization of cloned intracisternal A particle genes. Cell 1980; 21: 465-73.

[20] Shen-Ong GL, Cole MD. Differing populations of intracisternal Aparticle genes in myeloma tumors and mouse subspecies. J Virol 1982; 42: 411-21.

[21] Kuff EL, Lueders KK. The intracisternal A-particle gene family: structure and functional aspects. Adv Cancer Res 1988; 51: 183276.

[22] Griswold MD. Action of FSH on mammalian Sertoli cells. The Sertoli cells: Clearwater. In: Russell LD, Griswold MD, Eds. Florida: Cache River Press 1993.

[23] Holsberger DR, Buchold GM, Leal MC, et al. Cell-cycle inhibitors p27Kip1 and p21Cip1 regulate murine Sertoli cell proliferation. Biol Reprod 2005; 72: 1429-36.

[24] Kamberi IA, De Vellis J, Bacleon ES, Inglish D. Hormonal patterns of the hypothalamo-pituitary-gonadal axis in the rat during postnatal development and sexual maturation. Endocrinology 1980 ; 75: $129-40$

[25] Kirby JD, Jetton AE, Cooke PS, et al. Developmental hormonal profiles accompanying the neonatal hypothyroidism-induced increase in adult testicular size and sperm production in the rat. Endocrinology 1992; 131: 559-65.

[26] Kuff EL, Smith LA, Lueders KK. Intracisternal A-particle genes in Mus musculus: a conserved family of retrovirus-like elements. Mol Cell Biol 1981; 1: 216-27.

[27] Lueders KK, Kuff EL. Intracisternal A-particle genes: identification in the genome of Mus musculus and comparison of multiple isolates from a mouse gene 11 library. Proc Natl Acad Sci USA 1980; 77: 3571-5.

[28] Nelson PN, Carnegie PR, Martin J, et al. Demystified. Human endogenous retroviruses. Mol Pathol 2003; 56: 11-8.

[29] Anway MD, Johnston DS, Crawford D, Griswold MD. Identification of a novel retrovirus expressed in rat Sertoli cells and granulosa cells. Biol Reprod 2001; 65: 1289-96.

[30] Lin CP, Lee RS. Size and genetic composition of long terminal repeat sequences in the mouse intracisternal A-particle gene 81 . Proc Natl Sci Counc Repub China B 1988; 12: 27-33.

[31] Prefontaine GG, Walther R, Giffin W, Lemieux ME, Pope L, Hache RJ. Selective binding of steroid hormone receptors to octamer transcription factors determines transcriptional synergism at the mouse mammary tumor virus promoter. J Biol Chem 1999; 274: $26713-9$

[32] List HJ, Lozano C, Lu J, Danielsen M, Wellstein A, Riegel AT. Comparison of chromatin remodeling and transcriptional activation of the mouse mammary tumor virus promoter by the androgen and glucocorticoid receptor. Exp Cell Res 1999; 250: 414-22.

[33] List HJ, Smith CL, Martinez E, Harris VK, Danielsen M, Riegel AT. Effects of antiandrogens on chromatin remodeling and transcription of the integrated mouse mammary tumor virus promoter. Exp Cell Res 2000; 260: 160-5.

[34] Keydar I, Ohno T, Nayak R, et al. Properties of retrovirus-like particles produced by a human breast carcinoma cell line: immunological relationship with mouse mammary tumor virus proteins. Proc Natl Acad Sci USA 1984; 81: 4188-92.

[35] Patience C, Simpson GR, Colletta AA, Welch HM, Weiss RA, Boyd MT. Human endogenous retrovirus expression and reverse transcriptase activity in the T47D mammary carcinoma cell line. J Virol 1996; 70: 2654-7. 
[36] Dorrington JH, Armstrong DT. Follicle-stimulating hormone stimulates estradiol-17beta synthesis in cultured Sertoli cells. Proc Natl Acad Sci USA 1975; 72: 2677-81.

[37] Dorrington JH, Fritz IB, Armstrong DT. Site at which FSH regulates estradiol-17beta biosynthesis in Sertoli cell preparations in culture. Mol Cell Endocrinol 1976; 6: 117-22.
[38] Dorrington JH, Fritz IB, Armstrong DT. Control of testicular estrogen synthesis. Biol Reprod 1978; 18: 55-64.

[39] Sriraman V, Sairam MR, Rao AJ. Evaluation of relative roles of LH and FSH in regulation of differentiation of Leydig cells using an ethane 1,2-dimethylsulfonate-treated adult rat model. J Endocrinol 2003; 176: 151-61.

(C) Morrell and Rodriguez-Martinez; Licensee Bentham Open.

This is an open access article licensed under the terms of the Creative Commons Attribution Non-Commercial License (http: //creativecommons.org/licenses/by-nc/ 3.0/) which permits unrestricted, non-commercial use, distribution and reproduction in any medium, provided the work is properly cited. 